OPEN ACCESS

Edited by:

Yigang $X u$,

Zhejiang A\&F University, China

Reviewed by:

Sib Sankar Giri,

Seoul National University, South Korea

Qing Wang,

Chinese Academy of Fishery Sciences,

China

${ }^{*}$ Correspondence:

Jia-Yun Yao

yaojiayun@126.com

Hai-Qi Zhang

zmk407@126.com

Chun-Feng Wang

wangchunfeng@jlau.edu.cn

Specialty section:

This article was submitted to

Microbial Immunology,

a section of the journal

Frontiers in Immunology

Received: 11 January 2022 Accepted: 07 February 2022

Published: 04 March 2022

Citation:

Yao J-Y, Zhang C-S, Yuan X-M, Huang L, Hu D-Y, Yu Z, Yin W-L, Lin L-Y, Pan $X-Y$, Yang G-I, Wang C-F, Shen J-Y and Zhang H-Q (2022) Oral Vaccination With Recombinant Pichia pastoris Expressing Iridovirus Major

Capsid Protein Elicits Protective Immunity in Largemouth Bass (Micropterus salmoides).

Front. Immunol. 13:852300. doi: 10.3389/fimmu.2022.852300

\section{Oral Vaccination With Recombinant Pichia pastoris Expressing Iridovirus Major Capsid Protein Elicits Protective Immunity in Largemouth Bass (Micropterus salmoides)}

Jia-Yun Yao ${ }^{1 *}$, Cheng-Sai Zhang ${ }^{1}$, Xue-Mei Yuan ${ }^{1}$, Lei Huang ${ }^{1}$, Da-Yan $\mathrm{Hu}^{2}$, Zhe $\mathrm{Yu}^{1}$, Wen-Lin Yin ${ }^{1}$, Ling-Yun Lin ${ }^{1}$, Xiao-Yi Pan ${ }^{1}$, Gui-lian Yang ${ }^{3}$, Chun-Feng Wang ${ }^{3 *}$, Jin-Yu Shen ${ }^{1}$ and Hai-Qi Zhang ${ }^{1 *}$

\footnotetext{
${ }^{1}$ Agriculture Ministry Key Laboratory of Healthy Freshwater Aquaculture, Key Laboratory of Fish Health and Nutrition of Zhejiang Province, Zhejiang Institute of Freshwater Fisheries, Huzhou, China, ${ }^{2}$ Development Center of Huzhou Agricultural Science and Technology, Huzhou, China, ${ }^{3}$ College of Animal Science and Technology, Jilin Agricultural University, Changchun, China
}

Largemouth bass iridovirus (LMBV) can cause high mortality and lead to heavy economic loss in the cultivation of largemouth bass, but there was no effective treatment. Here, the present study constructed a recombinant Pichia pastoris expressing LMBV major capsid protein (MCPD). The recombinant GS115-pW317-MCPD was then used to immunize largemouth bass via oral administration, and mucosal immune response mediated by immunoglobulins (Igs) was measured after oral immunization. Serum antibody levels were measured by ELISA, neutralizing antibody titers were determined by serum neutralization test (SNT), antigen presentation-related gene expressions were detected by RT-PCR, and the histopathological characteristics of immunized fish were assessed after challenging with $0.1 \mathrm{ml} 10^{7.19} \mathrm{TCID}_{50} / \mathrm{ml} \mathrm{LMBV}$. The relative percentage survival (RPS) was also determined. Our results showed that the serum antibody titers of immunized fish were significantly higher than that of control groups $(P<0.05)$. IgT and IgM expressions in gut were increased significantly after vaccination with GS115-pW317-MCPD; however, much stronger response in gut was observed as compared with gill. The expression levels of major histocompatibility complex $(\mathrm{MHC}) \mathrm{II}, \mathrm{CD} 8$, and T-cell receptor (TCR) were significantly elevated in GS115-pW317-MCPD group $(\mathrm{P}<0.05)$, while CD4 and $\mathrm{MHC}$ I transcription levels remained unchanged after oral immunization $(P>0.05)$. The RPS of fish orally immunized with $1.0 \times 10^{8} \mathrm{CFU} / \mathrm{g}$ GS115-pW317-MCPD was reached up to $41.6 \%$ after challenge with $0.1 \mathrm{ml} 10^{9.46} \mathrm{TCID}_{50} / \mathrm{ml} \mathrm{LMBV}$. Moreover, orally immunizing with GS115-pW317-MCPD can relieve the pathological damage caused by LMBV. Therefore, GS115-pW317-MCPD showed a promising potential against LMBV.

Keywords: largemouth bass iridovirus, Pichia pastoris, immune protection, oral vaccines, presentation-related genes, immunoglobulins 


\section{INTRODUCTION}

Largemouth bass (Micropterus salmoides) was a widely cultured freshwater fish in China $(1,2)$. Since 2009, it has been suffering an outbreak of iridovirus disease, which was caused by largemouth bass virus (LMBV) (3). Frequent outbreaks of the disease may hinder the development of largemouth bass aquatic industry (4), so there are urgent needs for effective ways to control the disease.

Currently, there are still no effective chemical drugs used to control the outbreak of LMBV; also, drug residues, food, and environmental safety caused by excessive use of drugs are other disadvantages of chemotherapy (5). Vaccine is the most effective tool to prevent and control fish diseases; it was also considered as an effective way to reduce the use of chemical drugs (6). According to the preparation method of the vaccine, it can be divided into inactivated vaccine, live vaccine, and subunit and biotechnology vaccine. There are three main vaccine delivery ways in fish: injection, immersion, and oral administration, among which injection was the most effective way. However, injection was not suitable for large-scale operation in aquaculture; meanwhile, it could hamper the growth of immunized aquatic animals $(7,8)$. Immersion was another common immunization route, but a low immune effect limited its use in aquaculture. So, the urgent need of new methods for fish immunization has become the consensus of the aquaculture industry and academia. More and more effort has been made to pursue more convenient and efficacious immune methods to control fish disease $(9,10)$. Oral immunization has become the focus research topic due to its convenience in actual production (11). The greatest advantage of oral immunization was that it can trigger mucosal and systemic immune responses via activated dendritic cells (DCs) $(12,13)$, which then metastasizes to mesenteric lymph nodes (MLNs) and presents processed antigens to $\mathrm{T}$ and $\mathrm{B}$ lymphocytes. On the other hand, it is easy to elicit a rapid local innate immune response in the intestine.

Yeast is an ideal protein preparation platform; it was easy to culture and suitable for large-scale production. Additionally, $\beta$ glucan, the main compound of the cell wall of yeast, was recognized as an immune-stimulant supplement in fish, which made the yeast an attractive candidate for antigen delivery to the intestinal mucosa (14). On the other hand, it is very easy to administer with no stress to fish of various sizes and ages. In this study, Pichia pastoris GS115 was used as a host to express the LMBV major capsid protein (MCP) and introduced into $P$. pastoris GS115 by electroporation. Then, orally immunized to largemouth bass. Serum antibody levels of fish immunized with recombinant GS115-pW317-MCPD were measured by ELISA, neutralizing antibody titers were determined by SNT, and immune response of immunoglobulins (Igs) and antigen presentation-related gene expressions were detected by RTPCR. The relative percentage survival (RPS) and the histopathological characteristics of immunized fish were also assessed.

\section{MATERIALS AND METHODS}

\subsection{Fish}

Healthy largemouth bass $(24.6 \pm 3.1 \mathrm{~g})$ were purchased from Zhejiang Institute of Freshwater Fisheries Comprehensive Experimental Base (Zhejiang, China) and were acclimatized in recirculating aquaculture system for 14 days. Before the experiment, fish were randomly sampled for the examination of bacteria, parasite (microexamination), and virus (PCR for LMBV); no pathogens were detected, and no naturally dead fish were found during the temporary cultivation. Water quality conditions were controlled by recirculating the aquaculture system as follows: temperature: $28^{\circ} \mathrm{C} \pm 1^{\circ} \mathrm{C}$, dissolved oxygen $>5$ $\mathrm{mg} \mathrm{l}^{-1}$; nitrites $<0.02 \mathrm{mg} \mathrm{l}^{-1}$; ammonia $<0.1 \mathrm{mg} \mathrm{l}^{-1}$.

\subsection{Virus and Cell Lines}

The LMBV was originally isolated and identified from diseased largemouth bass by our laboratory. Fathead minnow (FHM) cell was obtained from Pearl River Fisheries Research Institute and grown at $28^{\circ} \mathrm{C}$ in Dulbecco's Modified Eagle Medium (DMEM) supplemented with $10 \%$ fetal bovine serum. Epithelioma papulosum cyprini (EPC) cells were maintained in our lab and grown at $28^{\circ} \mathrm{C}$ in DMEM. The $P$. pastoris GS115 was obtained from Hangzhou Fenghai Biotechnology Co., Ltd.

\subsection{Codon Optimization and Gene Synthesis}

Major epitope regions of $M C P D$ protein were analyzed and optimized (see in the attachment). In order to facilitate the purification of protein and antibody level determination, hexa-histidine tag was designed. The MCPD gene (hexa-histidine tag at the N-terminus) was synthesized by Sangon Biotech (Shanghai, China) Co., Ltd.

\subsection{Construction of Recombinant GS115- pW317-MCPD}

The primers for amplifying $M C P D$ were listed as follows: $\mathrm{F}$ : AATTGGTTTGACTAATTCCATAAT; R : AATGTTCGTCA AAATGGTGAC. EcoR I and NotI sites were also added, respectively (Figure 1). The pWB17 plasmid and the recombinant $\mathrm{pWB} 17-M C P D$ were integrated into $P$. pastoris GS115 by electroporation. Recombinant GS115-pW317-MCPD and GS115-pW317 were cultured in yeast extract peptone dextrose (YPD, containing $1,000 \mu \mathrm{g} / \mathrm{ml}$ zeocin) medium at $37^{\circ} \mathrm{C}$.

\subsection{Identification of Recombinant GS115-pW317-MCPD}

After induction for $24 \mathrm{~h}$, recombinant GS115-pW317-MCPD cells were harvested and then disrupted by sonication. The protein concentration of the culture lysates was then determined. The MCPD proteins were separated by Sodium Dodecyl Sulfate Polyacrylamide Gel Electrophoresis and then recombinant $M C P D$ proteins (with His-Tag) were identified by Western blotting using anti-His-tag monoclonal antibody and Horseradish Peroxidase (RRP)-conjugated goat anti-mouse IgG as antibodies (Beijing Solarbio Science \& Technology Co., Ltd.). 
A

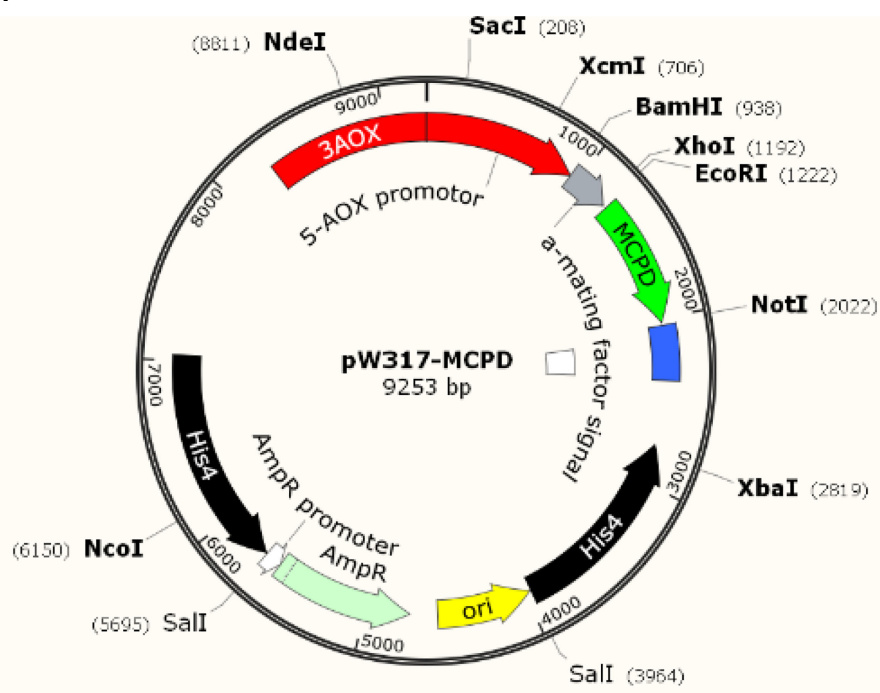

B

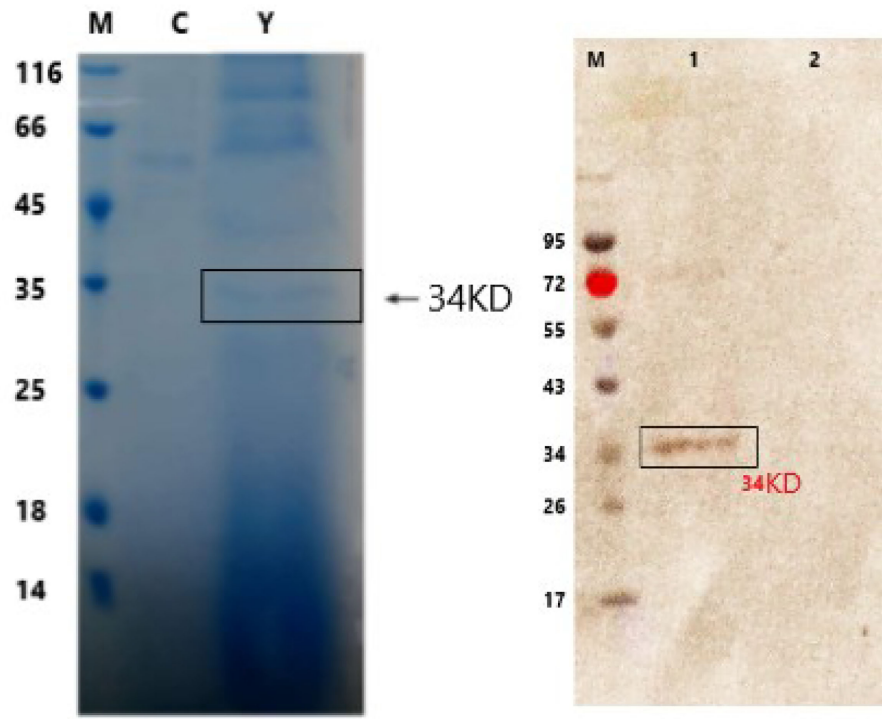

FIGURE 1 | Sodium dodecyl sulfate polyacrylamide gel electrophoresis (SDS- PAGE) and Western blot detection of recombinant truncated MCPD protein expression. (A) Plasmid map of pW317-MCPD. (B) SDS-PAGE and Western blot detection. M, protein standard molecular weight; C, blank control; Y, recombinant bacteria; 1, recombinant bacteria; 2, blank control.

\subsection{Assessment of Immune Efficacy of Recombinant GS115-pW317-MCPD}

\subsubsection{Oral Immunization and Experimental Design}

Five groups of fish (30 each) were orally immunized with $10^{8}$ CFU/g GS115-pW317-MCPD (commercial basal diet + GS115pW317-MCPD), $10^{7}$ CFU/g GS115-pW317-MCPD (commercial basal diet + GS115-pW317-MCPD), GS115-pW317 (10 ${ }^{8} \mathrm{CFU} / \mathrm{g}$ and $10^{7} \mathrm{CFU} / \mathrm{g}$ ), and PBS (commercial basal diet+PBS). Briefly, the harvested GS115-pW317-MCPD and GS115-pW317 were washed twice with PBS, and then the concentrations of harvested GS115-pW317-MCPD and GS115-pW317 were determined, and the required amount of GS115-pW317-MCPD and GS115-
pW317 was mixed with commercial basal diet for oral immunization. All fish were fed twice for 1 day at 08:00 and 16:00 h, respectively. The feeding trial was conducted for 2 weeks. Sera were collected from the caudal vein of each fish for antibody titer determination. Gill, gut, and kidney were sampled on days $7,14,21,28$, and 35 for immune response and gene expression assays ( 3 fish/time point). All treatments and control groups were conducted with three replicates (30 fish for each).

\subsubsection{Detection of Anti-MCPD Antibody}

The antibody levels of immunized fish were determined by ELISA according to previous studies $(6,10)$. Three largemouth 
bass were randomly selected from each group, serum from each fish was obtained and then diluted by $50 \mathrm{mM} \mathrm{Na} \mathrm{CO}_{3} / \mathrm{NaHCO}_{3}$ buffer ( $\mathrm{pH}$ 9.6) at $37^{\circ} \mathrm{C}$ for $4 \mathrm{~h}$ (each conducted with three parallel repetitions). Purified $M C P D$ protein (with His-Tag) was then added into 96 -microtiter plate at $37^{\circ} \mathrm{C}$; after incubation for $1 \mathrm{~h}$, each well was washed with Phosphate Buffered Saline with $0.05 \%$ Tween (PBST) 3 times. Here, $100 \mu$ of McAb Mouse AntiHis Tag $(1: 2,500)$ used as primary antibody were then added into each well of plate at $37^{\circ} \mathrm{C}$ for $1 \mathrm{~h}$, then washed with PBST buffer 3 times. Subsequently, HRP-conjugated goat-mouse IgG antibody $(1: 2,000)$ used as secondary antibody was added into each well of plate at $37^{\circ} \mathrm{C}$; after incubation for $1 \mathrm{~h}$, each well was washed by PBST buffer 3 times, then $2 \mathrm{~mol} / \mathrm{L} \mathrm{H}_{2} \mathrm{SO}_{4}$ were used to stop the reaction; Tetramethylbenzidine (TMB) was used to color the result.

\subsubsection{Immune Response of Immunoglobulins}

Gene expression levels of IgM and IgT after immunization were conducted. Total RNA extracted from each tissue (gill, gut, and kidney) was prepared by TRIzol lysis (Invitrogen, USA). cDNA was then synthesized according to the protocol of Reverse Transcriptase M-MLV Kit (TaKaRa, Dalian, China). The RTPCR was performed using THUNDERBIRD SYBR qPCR Mix Kit (TOYOBO, Shanghai, China). The primer was designed following previous reports $(15,16)$.

\subsubsection{Antigen Presentation-Related Gene Expression}

Expression levels of antigen presentation-related genes major histocompatibility complex (MHC) I, MHC II, CD8, CD4, and Tcell receptor (TCR) were also determined by RT-PCR. Briefly, total RNA was extracted from gill, gut, and kidney by TRIzol Reagent (Cwbio, Beijing, China). The RT-PCR was performed using THUNDERBIRD SYBR qPCR Mix Kit (TOYOBO, Shanghai, China) and carried out in a Stratagene MxPro System (Stratagene mx3005p, USA) in 96-well reaction plates.

\subsubsection{Serum Neutralization Test}

Neutralizing antibody titers were determined by serum neutralization test (SNT) in EPC cells according to previous methods (17). Firstly, harvested sera were doubly serially diluted in DMEM (without Fatal Bovine Serun), and then $50 \mu$ of serum was mixed with the same volume of DMEM and 100 tissue $\mathrm{TCID}_{50}$ of virus. Secondly, $100 \mu \mathrm{l}$ preincubated mixture $\left(25^{\circ} \mathrm{C}\right.$ for $1 \mathrm{~h}$ ) were added to EPC cell monolayers. Finally, 5 days after incubation, the highest dilution at which 50\% EPC cells were inhibited was considered as the LMBV neutralizing antibody titer.

\subsubsection{Histological Evaluation}

At 35 days post immunization (dpi), three largemouth bass were randomly selected from group GS115-pW317-MCPD and GS115-pW317 and injected $0.1 \mathrm{ml} 10^{8.66} \mathrm{TCID}_{50} / 30 \mathrm{ml} \mathrm{LMBV}$ per fish, six largemouth bass were randomly selected from PBS group, three fish were challenged with $0.1 \mathrm{ml} 10^{7.19} \mathrm{TCID}_{50} / \mathrm{ml}$ $\mathrm{LMBV}$, the remaining three fish were treated with no virus. After 14 days, the liver, kidney, and spleen samples in each group were received, fixed in $10 \%$ formalin, embedded in paraffin wax, and sectioned by microtome, and then hematoxylin and eosin (H\&E) staining was conducted to analyze the histological change of immunized fish.

\subsection{Challenge Test}

Five groups were set in challenge test. Each group contains 20 largemouth bass; each group was performed with three replicates. Immunized groups were orally immunized with GS115-pW317-MCPD (commercial basal diet + GS115pW317-MCPD $10^{7}$ CFU/g feed) and GS115-pW317-MCPD (commercial basal diet + GS115-pW317-MCPD $10^{8} \mathrm{CFU} / \mathrm{g}$ feed). GS115-pW317 (10 ${ }^{7} \mathrm{CFU} / \mathrm{g}$ feed and $\left.10^{8} \mathrm{CFU} / \mathrm{g}\right)$ and PBS (commercial basal diet+PBS) served as control group. All fish were fed twice a day and lasted for 2 weeks. On $21 \mathrm{dpi}$, all fish were challenged with $0.1 \mathrm{ml} 10^{9.46} \mathrm{TCID}_{50} / \mathrm{ml} \mathrm{LMBV}$ per fish. Mortalities in each group were recorded daily for 15 days. The RPS was calculated as follows:

RPS $(\%)=($ mortality of immunized group $\%-$ mortality of control group \% )/mortality of control group $\%$.

\subsection{Data Analysis}

The data were expressed as the mean and standard deviation (mean \pm SD) and analyzed by Statistical Product and Service Solutions (SPSS 19.0). The difference was considered statistically significant when $\mathrm{P}<0.05$ and highly significant when $\mathrm{P}<0.01$.

\section{RESULTS}

\subsection{Construction of Recombinant GS115-pW317-MCPD}

GS115-pW317-MCPD (Figure 1A) was constructed and introduced into $P$. pastoris GS115 by electroporation. The cell lysates GS115-pW317-MCPD and GS115-pW317 were subjected to SDS-PAGE and Western blot. A specific band of about $43 \mathrm{kDa}$ was detected in GS115-pW317-MCPD (Figure 1B), but no band was found in GS115-pW317 (Figure 1B), which indicated that $M C P D$ was successfully expressed in P. pastoris GS115.

\subsection{Assessment of Immune Efficacy of Recombinant GS115-pW317-MCPD}

\subsubsection{Detection of Anti-MCPD Antibody}

Results from ELISA showed that the antibody levels in GS115pW317-MCPD-immunized group were significantly higher than those of fish fed GS115-pW317 or PBS $(P<0.01)$. Serum antibody levels in $10^{8} \mathrm{CFU} / \mathrm{g}$ GS115-pW317-MCPD-immunized group were about 8-fold higher than those in the PBS group and GS115-pW317 group (Figure 2); the highest antibody level was detected on $28 \mathrm{dpi}$.

\subsubsection{Immune Response of Immunoglobulins}

The expression levels of IgM in all tested tissues were significantly increased after oral immunization. After oral immunization, IgM had highest expression in the kidney followed by gut. The expression level of $\operatorname{IgM}$ in the kidney 


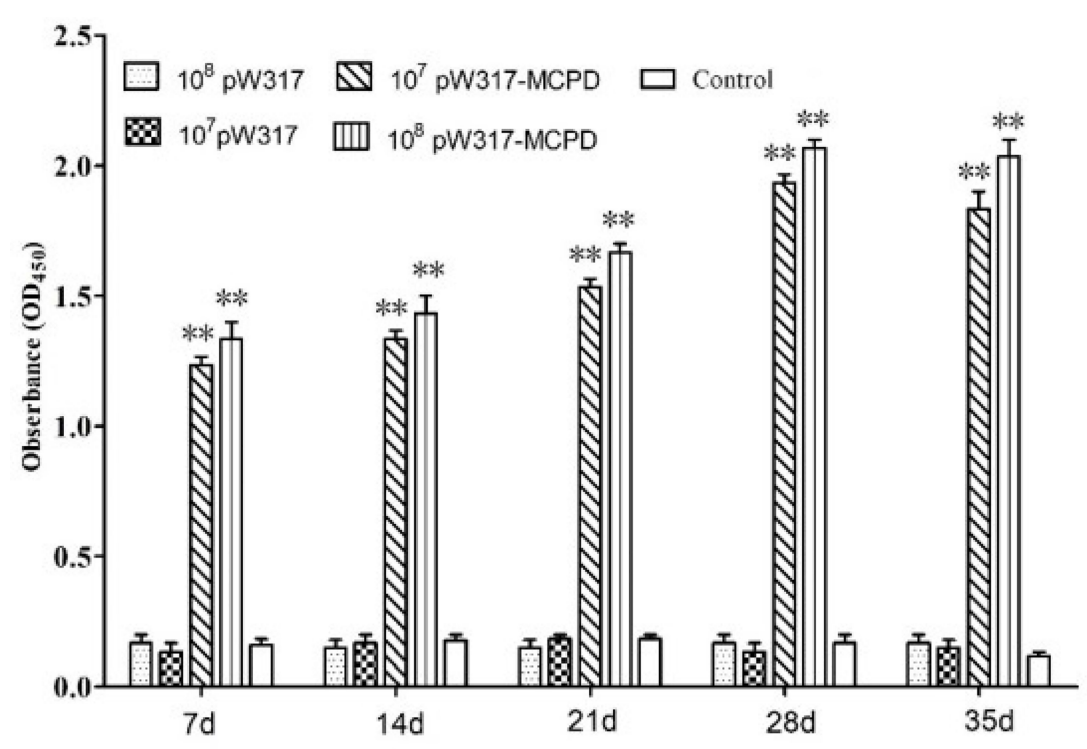

FIGURE 2 | The levels of serum antibody. Serum was collected from the fish at 7, 14, 21, 28, and 35 dpi, and serum antibodies against MCPD were determined by ELISA. Three replicates were set for the tests, with three fish per replicate. Data are means for three assays and presented as the means \pm SE. ${ }^{\star *}<0.01$. 107 pW317: $10^{7}$ CFU/g GS115-pW317; $10^{8}$ pW317: $10^{8}$ CFU/g GS115-pW317; $10^{7}$ pW317-MCPD: 107 CFU/g GS115-pW317-MCPD; 10 pW317-MCPD: 10 ${ }^{8}$ CFU/g GS115-pW317-MCPD.

increased firstly and then decreased slowly, reached a peak at 28 dpi, which was about 11 -fold higher than that in the PBS group. Interestingly, the IgM mRNA level in GS115-pW317 group was significantly higher than that in the PBS group in gut and head kidney at 21, 28, and 35 dpi $(\mathrm{P}<0.05)$.

Compared with GS115-pW317 and PBS control groups, IgT was highly expressed in head kidney and gut. In head kidney, the IgT gene expression reached its peak at $21 \mathrm{dpi}$, which was about 12 -fold higher than that in the control PBS group; the corresponding data in gut was 5.5-fold. However, much stronger response in gut was observed as compared with gill after oral immunization (Figure 3).

\subsubsection{Antigen Presentation-Related Gene Expression}

The RT-PCR analysis showed that the expressions of $\mathrm{MHC}-\mathrm{I}$ mRNA in the tested tissues were increased as compared with those in the control group after oral immunization. In gill, the expressions of MHC-I mRNA in GS115-pW317-MCPDimmunized group were significantly upregulated and reached the top at $21 \mathrm{dpi}$, which was 2.4-fold higher than those in the PBS groups (Figure 4). However, no difference was found in gut tissue (Figure 5). The peak value of kidney tissue was 3.8 times higher than that of the PBS group on $28 \mathrm{dpi}$ (Figure 6).

The mRNA expressions of MHC II in GS115-pW317-MCPDimmunized group were significantly upregulated as compared with those in the control group $(\mathrm{P}<0.01)$. In kidney, the expression level of $M H C$ II reached up to a peak at $21 \mathrm{dpi}$, which was 2.4-fold higher than that in the PBS group. In gut, the peak value of $10^{8} \mathrm{CFU} / \mathrm{g}$ group was found at $21 \mathrm{dpi}$, which was 4.5-fold higher than that in the PBS group (Figure 5).

The results of mRNA expressions of CD4 in kidney, gut, and gill were shown in Figures 4-6. In kidney, the relative expression of CD4 transcript level in the immunized group was significantly upregulated and reached its peak at dpi 28; similar results were also detected in gill. However, in gut, both immunized groups showed no difference compared with PBS group and empty carrier group $(\mathrm{P}>0.05)$.

The mRNA expressions of CD8 in kidney, gut, and gill were significantly increased as compared with those in the control group $(\mathrm{P}<0.01)$ (Figure 4). In kidney, the expressions of CD8 mRNA were significantly upregulated at $28 \mathrm{dpi}$ as compared with those in the PBS group $(\mathrm{P}<0.01)$ (Figure 6). In gut, the peak value of $10^{8} \mathrm{CFU} / \mathrm{g}$ group was found at 28 dpi, which was 4.2-fold higher than that in the PBS group (Figure 5).

The RT-PCR analysis showed that the expressions of TCR mRNA in the three tested tissues were increased as compared with those in the control group. The peak value of kidney tissue was 2.6 times higher than that of the PBS group on $28 \mathrm{dpi}(\mathrm{P}<$ 0.01 ). In gill, the expressions of TCR mRNA reached up to a peak at $35 \mathrm{dpi}$, with a peak value of 2.2-fold higher than that of the PBS group (Figure 4).

\subsubsection{Histopathological Analysis}

Varying degrees of cytopathic lesions were detected in largemouth bass after challenging with LMBV, however, in the control group treated with non virus, cells were normal with intact structure, and no pathological changes were found (Figures 7A, E, I). Hepatic sinus dilatation and congestion, hepatic cell swelling and vacuolar degeneration, and steatosis were found in the liver of largemouth bass after challenging with LMBV (Figures 7B-D). The splenic sinus was diluted and filled with pink serous fluid, and a large number of red blood cells were 

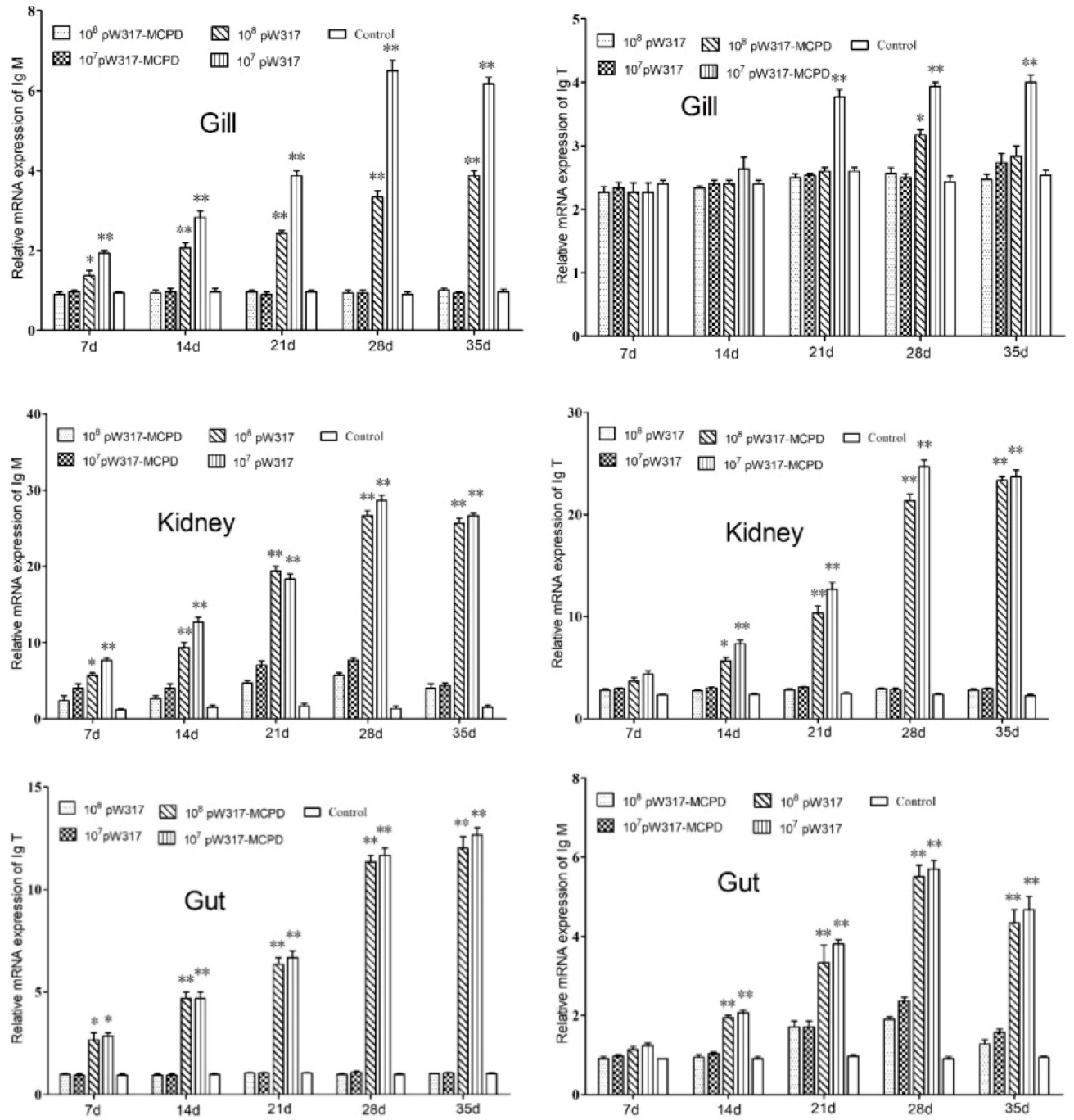

FIGURE 3 | The expression level of lgM and IgT in different tissues after immunization. 107 pW317: 10 ${ }^{7}$ CFU/g GS115-pW317; 10 ${ }^{8}$ pW317: 10 ${ }^{8}$ CFU/g GS115pW317; $10^{7}$ pW317-MCPD: $10^{7}$ CFU/g GS115-pW317-MCPD; $10^{8}$ pW317-MCPD: $10^{8}$ CFU/g GS115-pW317-MCPD. **P < 0.01; ${ }^{*}$ < 0.05.

detected in the spleen (Figures $7 \mathbf{F}-\mathbf{H}$ ). Tubule epithelial cells were highly swollen and partially separated from the basal side of the renal tubules (Figures $7 \mathbf{J}-\mathbf{L}$ ). However, the pathological injuries in spleen and kidney were relatively light when immunized with $10^{8}$ CFU/g GS115-pW317-MCPD.

\subsubsection{Serum Neutralization Test}

The results of SNT were shown in Figure 8. Antibody titers in $10^{8} \mathrm{CFU} / \mathrm{g}$ GS115-pW317-MCPD-immunized group were significantly higher than those in GS115-pW317 and PBS groups; the peak titer in $10^{8} \mathrm{CFU} / \mathrm{g}$ GS115-pW317-MCPD was 1:64 at dpi 28, while the peak titer in $10^{7} \mathrm{CFU} / \mathrm{g}$ group was 1:32.

\subsection{Challenge Test}

The challenged largemouth bass began to die on day 4 in PBS group; 96.7\% mortality was found in GS115-pW317 and PBS groups. However, the immunized group began to die on day 6 ; the mortality of fish immunized with both doses of pW317$M C P D$ was significantly reduced $(\mathrm{P}<0.01)$ (Figure 9). The RPS of $10^{8} \mathrm{CFU} / \mathrm{g}$ GS115-pW317-MCPD and $10^{7} \mathrm{CFU} / \mathrm{g}$ GS115pW317-MCPD was $41.6 \%$ and $33.3 \%$, respectively.

\section{DISCUSSION}

LMBV was one of the most harmful viruses in the cultivation of largemouth bass. However, there is still no effective drug to treat LMBV infection. Vaccination is considered as an effective method to control the outbreak of fish disease (18). The route of immunization plays a vital role in the effectiveness of vaccine. There were three main immunization routes in aquaculture: bath/immersion, injection, and oral administration (19). Oral immunization was the preference because it can be used for mass vaccination, and it is relatively easy and stress-free. In the present 

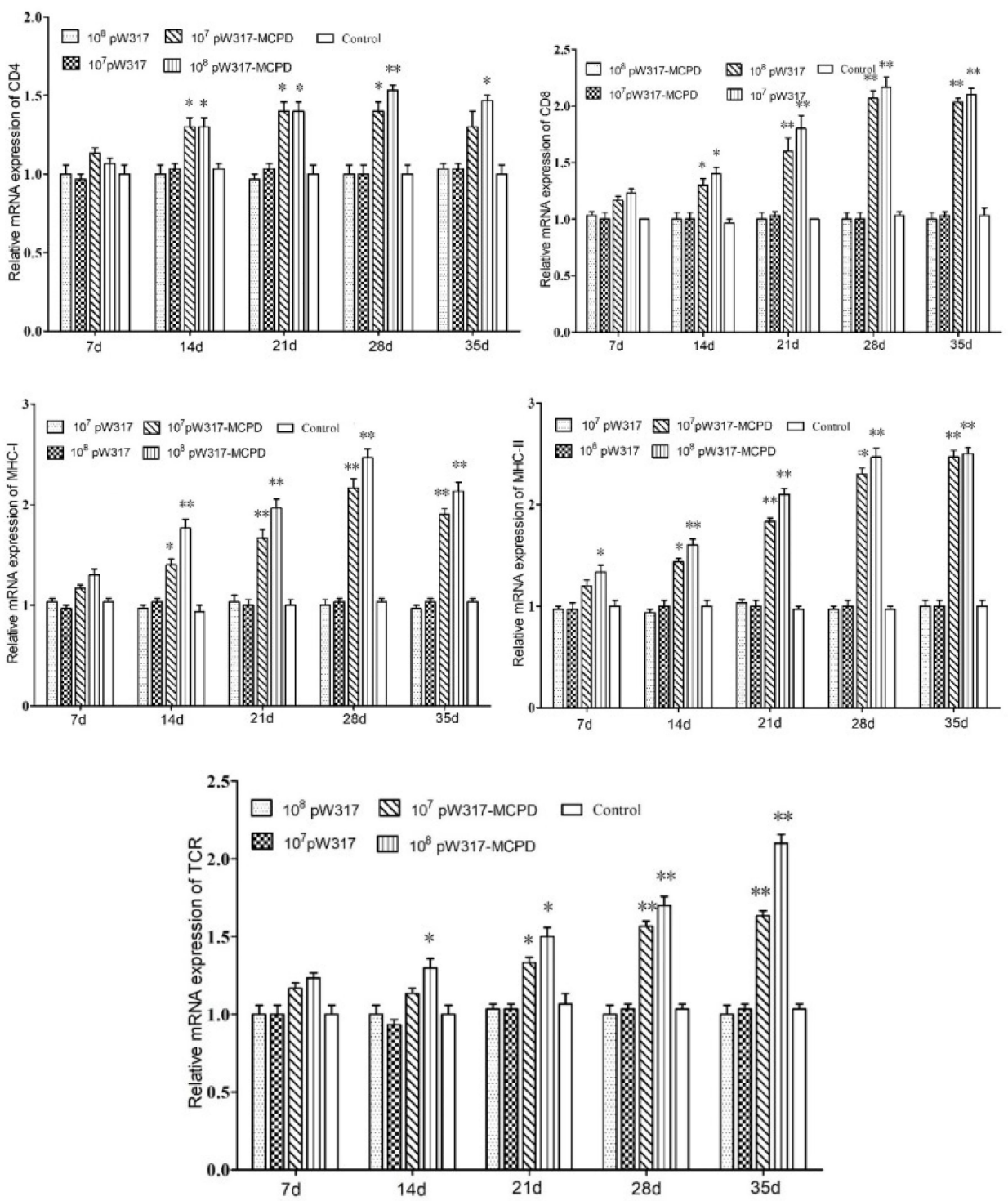

FIGURE 4 | The expression level of antigen presentation-related gene in gill after immunization. $10^{7} \mathrm{pW} 317: 10^{7} \mathrm{CFU} / \mathrm{g}$ GS115-pW317; $10^{8} \mathrm{pW} 317: 10^{8}$ CFU/g GS115-pW317; $10^{7}$ pW317-MCPD: $10^{7}$ CFU/g GS115-pW317-MCPD; $10^{8}$ pW317-MCPD: $10^{8}$ CFU/g GS115-pW317-MCPD. **P < 0.01; *P < 0.05.

study, an oral vaccine that expressed the MCP protein of LMBV was constructed via the yeast $P$. pastoris, and the results from the challenge test showed that GS115-pW317-MCPD can effectively elicit immunity response and protect largemouth bass against LMBV, which indicated that $P$. pastoris could become a promising oral vaccine carrier against fish virus.

Neutralizing antibody plays a vital role in defending against viral diseases of fish $(12,20)$. Results from the present study showed that the antibody titers reached up to 64 at $28 \mathrm{dpi}$, and the RPS of fish orally immunized with GS115-pW317-MCPD was $41.6 \%$. However, Yi et al. (21) reported that SN antibody titers could reach a peak with the value of 1:375 \pm 40 at 14 days after immunization via injection, which was almost 6-fold higher than our results. This may be because the immunological effect of injection was better than oral administration. Moreover, the content of antigen expressed by $P$. pastoris may not be enough for largemouth bass. So, more technology applied to improve immune efficacy is needed. Coexpression of antigen or some adjuvant-related protein can enhance the immune effect. Liu et al. (22) found that coexpression of influenza NP-M2 and a mucosal adjuvant (FliC) by Lactobacillus plantarum could enhance the protective immune responses against H9N2 influenza. Recent research demonstrated that coexpression of some invasion-related proteins can improve the immune effect. Fibronectin-binding proteins (FnBPA) were one of the most studied invasion-related proteins; it could invade mammalian 

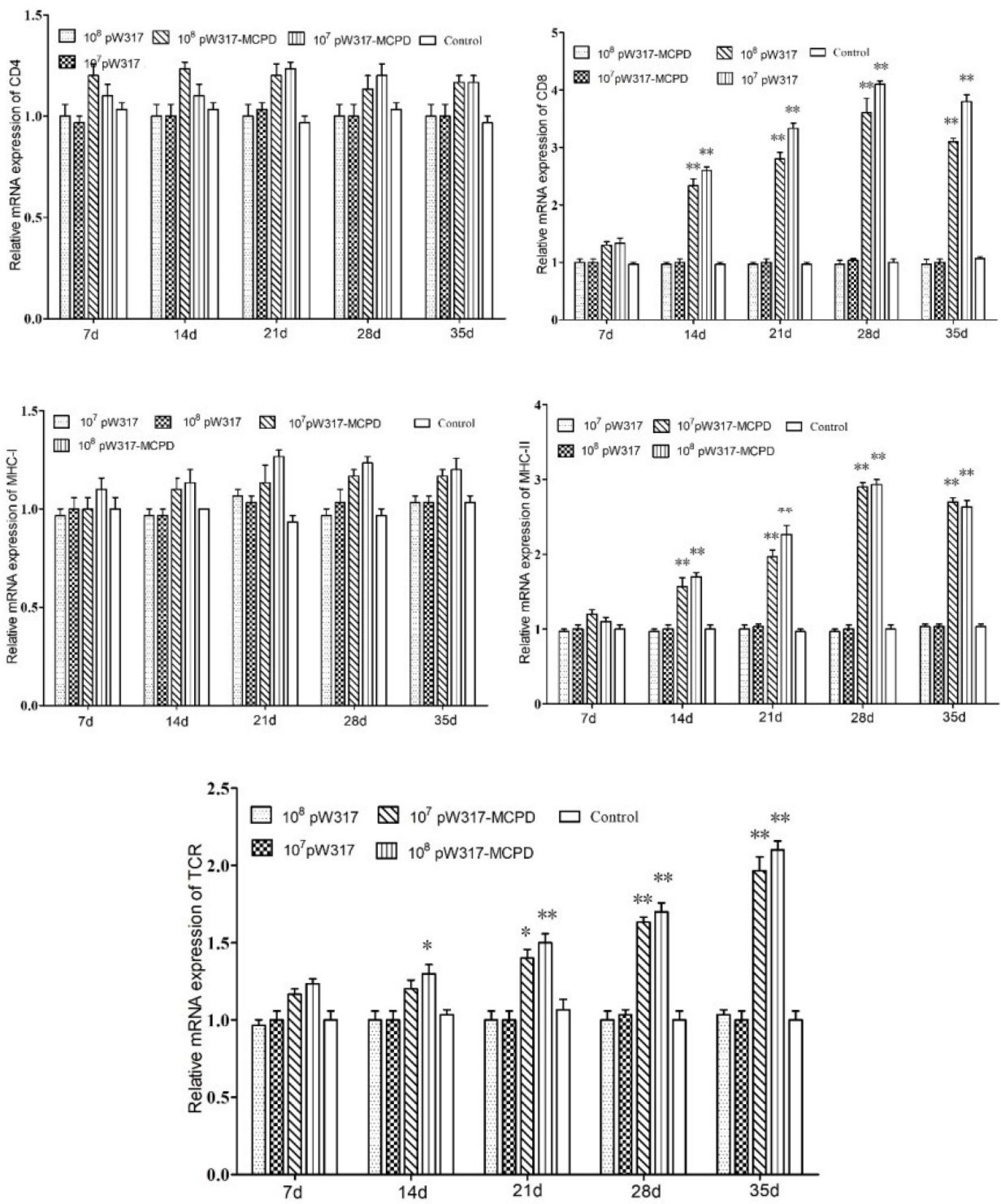

FIGURE 5 | The expression level of antigen presentation-related gene in gut after immunization. 10 $0^{7} \mathrm{pW} 317: 10^{7} \mathrm{CFU} / \mathrm{g}$ GS115-pW317; $10^{8} \mathrm{pW} 317: 10^{8} \mathrm{CFU} / \mathrm{g}$ GS115-pW317; $10^{7}$ pW317-MCPD: $10^{7}$ CFU/g GS115-pW317-MCPD; $10^{8}$ pW317-MCPD: $10^{8}$ CFU/g GS115-pW317-MCPD. **P $<0.01 ;{ }^{*} P<0.05$.

cells by binding to the $\alpha 5 \beta 1$ integrin on the surface of the host cell membrane. Therefore, it was usually used to carry DNA to host cells (23). Liu et al. (24) confirmed that invasive $L$. plantarum expressing the FnBPA protein enhanced humoral and cellular immunity and improved protective effectiveness against Eimeria tenella. Xue et al. (25) used the invasive $L$. plantarum (expressing FnBPA) as a live bacterial vector to coexpress Trichinella spiralis SS1 and murine interleukin-4; in vivo results exhibited that FnBPA increased the effect of antigen presentation and immune protection. Additional studies are required to further coexpress more antigens; some adjuvant or invasion-related proteins are needed to enhance the humoral and cellular immunity (26).
Igs are key element components of the immune response in teleost fish, playing a crucial role in protecting fish against various pathogens. So far, three major classes of Igs, IgM, IgD, and IgT/Z, were found in teleost fish (27). IgT, equivalent to that of mammalian IgA, was firstly detected in rainbow trout (Oncorhynchus mykiss) $(28,29)$. More and more research showed that $\operatorname{IgT}$ plays a key role in the mucosal immunity of teleost $(28,29)$. IgM is the best characterized teleost Ig isotype and plays an important role in systemic immunity (30). The expression levels of IgM in kidney, gut, and gill were significantly increased after oral immunization of GS115-pW317-MCPD and highest expressed in kidney followed by gut. Interestingly, the IgM mRNA level in GS115-pW317 group was significantly higher than that in 

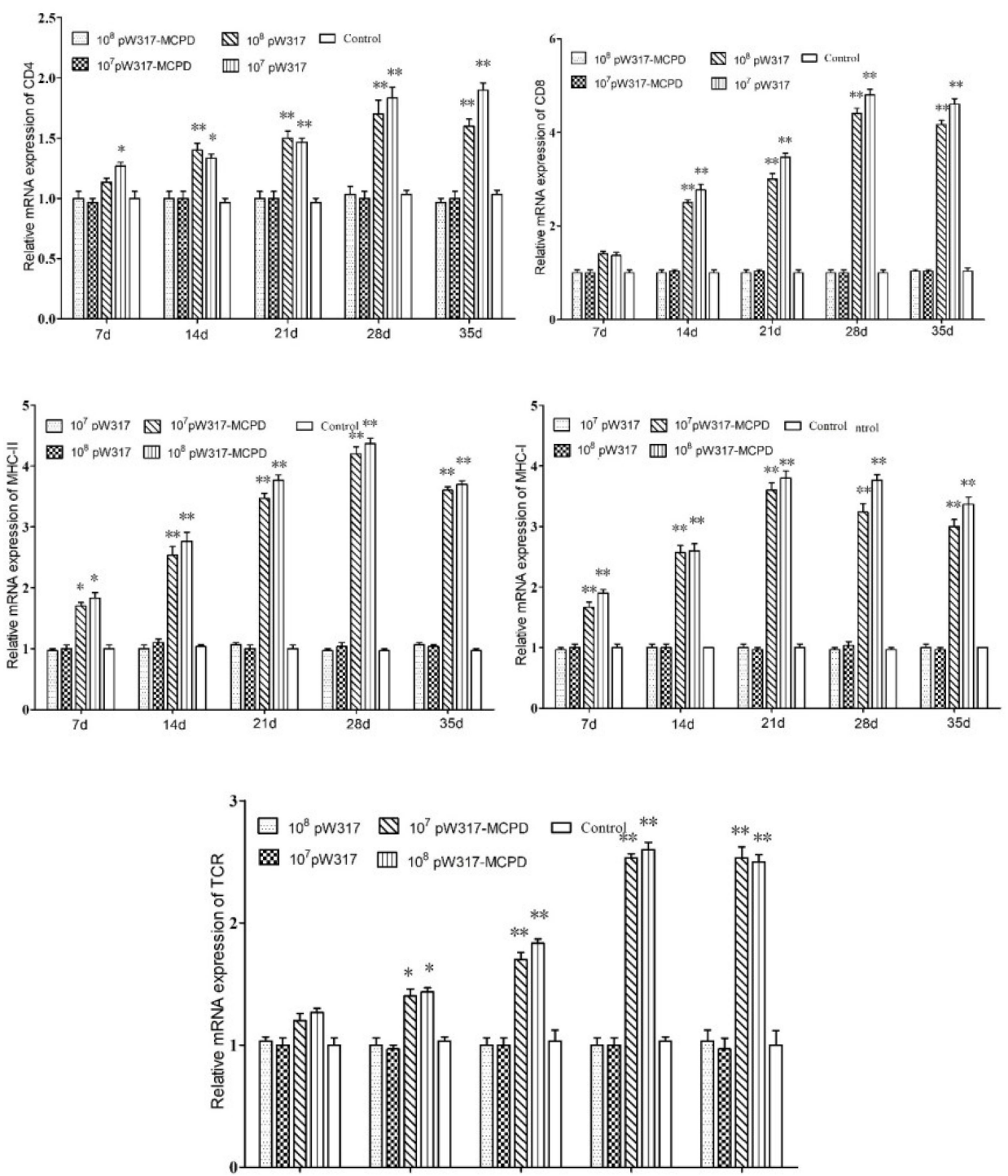

FIGURE 6 | The expression level of antigen presentation-related gene in head kidney after immunization. 107 pW317: 10 $\mathrm{CFU} / \mathrm{g}$ GS115-pW317; $10^{8} \mathrm{pW} 317: 10^{8}$ CFU/g GS115-pW317; $10^{7}$ pW317-MCPD: $10^{7}$ CFU/g GS115-pW317-MCPD; $10^{8}$ pW317-MCPD: $10^{8}$ CFU/g GS115-pW317-MCPD. ${ }^{* * P}<0.01 ;{ }^{*} P<0.05$.

the PBS group in gut and head kidney. This may be because the main cell wall component of yeast, $\beta$-glucan, has been characterized as a dietary immune-stimulant supplement that could increase complement activity and enhance the expression of IgM (14). As for IgT, after administering recombinant GS115$\mathrm{pW} 317-M C P D$, it was highly expressed in the head kidney and gut largemouth bass. Similar to our results, the expression level of IgT in largemouth bass was highest expressed in head kidney after immersion vaccination with Aeromonas hydrophila, then in spleen, liver, and gill. By contrast, the highest expression level of Ig tau heavy chain (IgT) in turbot and flounder was detected in gill and spleen $(31,32)$. Because IgT may exhibit fish species specificity (30). Our results also indicated that much stronger response of $\operatorname{IgT}$ was observed in gut after oral immunization; higher levels of $\operatorname{IgT}$ expression were observed in gut than in gill, which indicated that gut may be the main mucosal immunity site. Some studies have shown that sIgT and IgT+ cells in trout develop a stronger mucosal immune response than systemic immunity that indicated that IgT presented played a major role in mucosal immunity $(28,29)$. Based on the above, we speculated that intestinal tract plays an important role in mucosal immunity after oral immunization; also, IgT played a major important role in largemouth bass mucosal immunity.

Antigen handling and presentation play an important role in adaptive immunity. When the antigen binds to $M H C$ I and II, antigens are processed and presented to specific lymphocytes (33). MHC is a group of cell surface proteins that interact with T cells in the acquired immune system through TCR (34) and is a key 

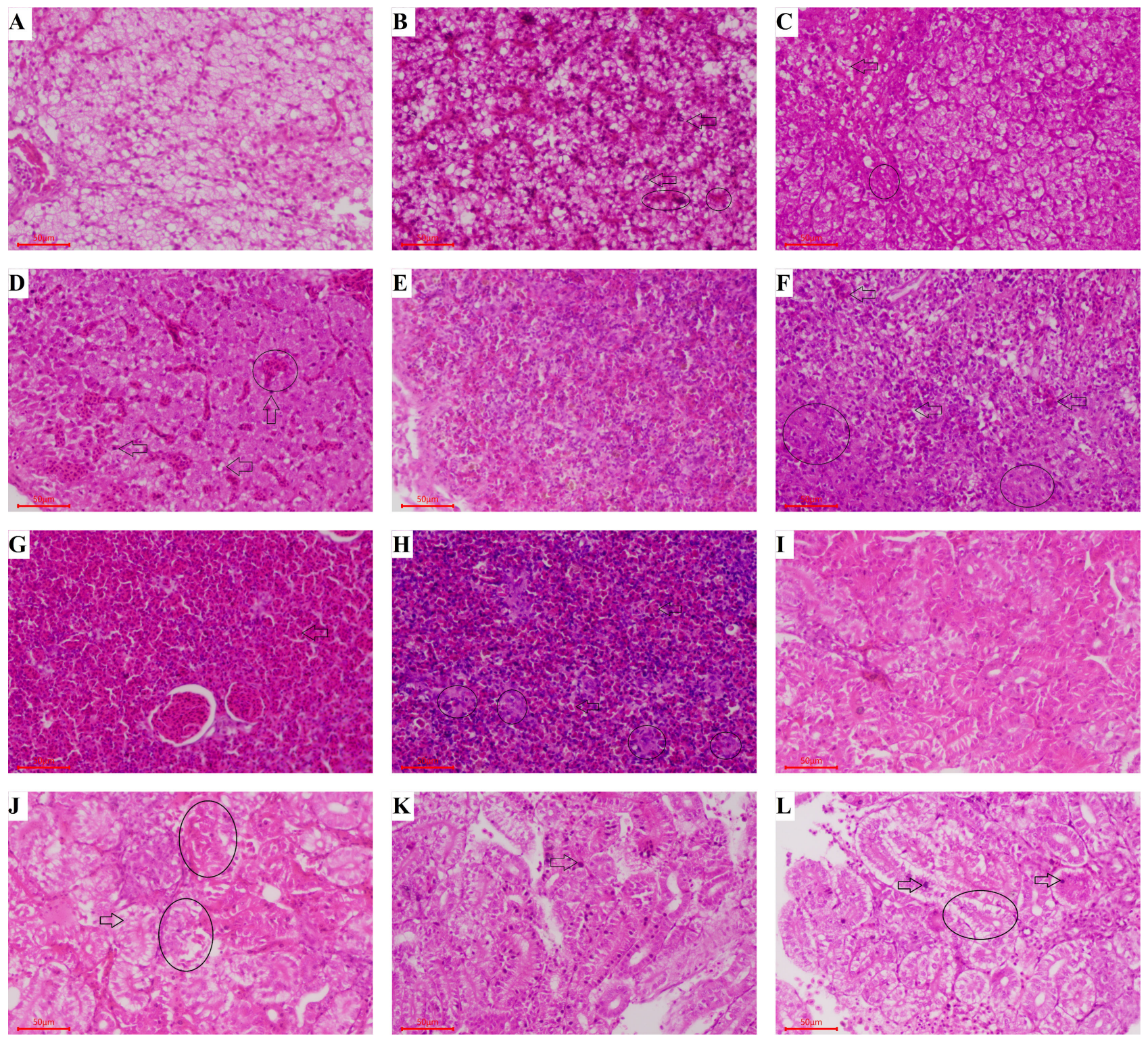

FIGURE 7 | Histopathological assessment of liver, spleen, and kidney from largemouth bass after challenge. Groups A, E, and I: Fed with commercial basal diet +PBS, treated with no virus; Groups B, F, and J: Fed with commercial basal diet+107 CFU/g GS115-pW317-MCPD, challenged with LMBV; Groups C, G, and K: Fed with commercial basal diet $+10^{8}$ CFU/g GS115-pW317-MCPD, challenged with LMBV; Groups D, H, and L: Fed with commercial basal diet+PBS, challenged with LMBV. (A) The structure of liver cell was integrated, and the gland was clearly visible. (B) Some hepatocytes were swollen and degenerated $(\Leftrightarrow)$ ), the chromatin edges are concentrated and moved into rings (O). (C) Hepatic cell swelling and vesicular degeneration were detected $(\Leftrightarrow)$ ), the chromatin edges are concentrated and moved into rings (O). (D) Hepatic sinus dilatation and congestion $(\Leftrightarrow)$, hepatic cell swelling and vacuolar degeneration and steatosis were found (O). (E) The spleen cells were normal with intact structure, and no pathological changes were found. (F) The splenic sinus was diluted and filled with pink serous fluid, a small amount of reticular cellulose and a large number of red blood cells were detected $(\Rightarrow)$, spleen structure is disordered and reticular cells increase $(\mathbf{O})$. (G) Some congestive spleen cells were found $(\Leftrightarrow)$. (H) Spleen sinuses were dilated and congested $(\mathrm{O})$, a large number of red blood cells were detected in the spleen tissue $(\Rightarrow)$. (I) The kidney cells were normal with intact structure. (J) Swelling and degeneration of renal tubular epithelial cells were detected $(\Leftrightarrow)$, tubule epithelial cells were swollen and separated from the basal side of the renal tubules (O). (K) Some swelling and degeneration of renal tubular epithelial cells were detected $(\Rightarrow)$. (L) Tubule epithelial cells were highly swollen $(\Rightarrow)$ and partially separated from the basal side of the renal tubules $(\mathrm{O})$.

protein for recognizing invading pathogens and stimulating immune responses. $M H C$ I and $M H C$ II recognize antigenic peptides mainly via TCR especially the protein chains on TCR-A and TCR-B (35). MHC I is an exogenous peptide produced by degradation of intracellular pathogens into cytotoxic $C D 8^{+} \mathrm{T}$ cells; additionally, $M H C$ I can recognize exogenous antigens and present to cytotoxic $\mathrm{T}$ cells through a mechanism called antigenic cross presentation (36). Some reports showed that MHC II plays an 


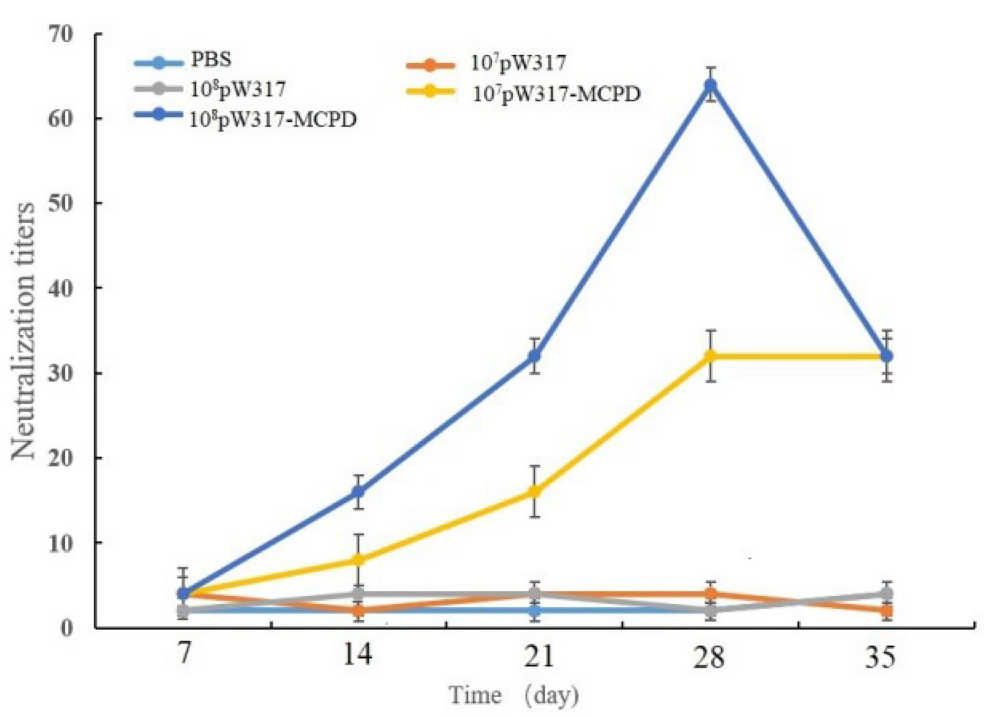

FIGURE 8 | Serum neutralization assay of largemouth bass after oral immunization. Note: 10 pW317: $10^{7} \mathrm{CFU} / \mathrm{g}$ GS115-pW317; 10 ${ }^{8} \mathrm{pW} 317: 10^{8} \mathrm{CFU} / \mathrm{g}$ GS115pW317; $10^{7}$ pW317-MCPD: $10^{7}$ CFU/g GS115-pW317-MCPD; $10^{8}$ pW317-MCPD: $10^{8}$ CFU/g GS115-pW317-MCPD.

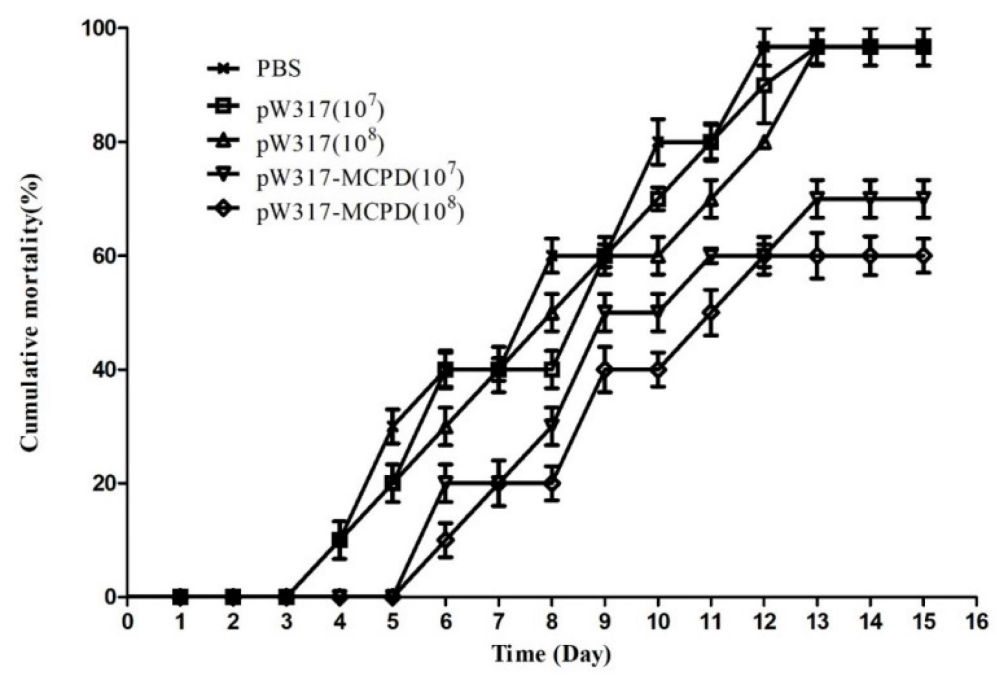

FIGURE 9 | The cumulative mortality of vaccinated largemouth bass. Note: $10^{7} \mathrm{pW} 317: 10^{7} \mathrm{CFU} / \mathrm{g}$ GS115-pW317; $10^{8} \mathrm{pW} 317: 10^{8} \mathrm{CFU} / \mathrm{g}$ GS115-pW317; 107 pW317-MCPD: $10^{7}$ CFU/g GS115-pW317-MCPD; $10^{8}$ pW317-MCPD: $10^{8}$ CFU/g GS115-pW317-MCPD.

important role in presenting the extracellular antigen to $C D 4^{+} \mathrm{T}$ cells (37). The results from the present study showed that $M H C$ II b, $C D 8$, and TCR were elevated, while $C D 4$ and $M H C$ I transcription levels remained unchanged after oral immunized with GS115-pW317-MCPD. Consistent with our research, Pichietti et al. (38) reported that the expression of CD8-a in posterior intestine was significantly elevated after immunization, while the expression of TCR-b and CD8-a was higher than that of CD4. By contrast, after immunizing with inactivated viruses via immersion and oral administration, the expression levels of $M H C$ I and CD8 mRNA were significantly upregulated in Dicentrarchus labrax and Epinephelus coioides (39-41); this indicated that a subset of CD8-ap T cells could bind antigens out of the context of MHC molecules that was also found in mammalian TCR-gd CD8aap IEL subset, which means that $M H C$-restricted peptide presentation was not absolutely required (42).

In conclusion, an oral vaccine using $P$. pastoris that expressed $M C P D$ has been developed to control LMBV. Our findings revealed 
that the $P$. pastoris yeast expression system was a promising vehicle for antigen delivery; it showed a good prospect in the application of fish oral vaccine. However, the mucosal immune mechanism should be included in future studies.

\section{DATA AVAILABILITY STATEMENT}

The original contributions presented in the study are included in the article/Supplementary Material. Further inquiries can be directed to the corresponding authors.

\section{ETHICS STATEMENT}

The animal study was reviewed and approved according to the guidelines of the Animal Experiment Committee, Zhejiang Institute of Freshwater Fishery (ZJIFF20210302).

\section{AUTHOR CONTRIBUTIONS}

JY, GY, WZ and HZ contributed to the conception of the study. JY, $\mathrm{XY}, \mathrm{CZ}$ constructed the recombinant GS115-pW317-MCPD. LH,

\section{REFERENCES}

1. Waters DS, Noble RL, Hightower JE. Fishing and Natural Mortality of Adult Largemouth Bass in a Tropical Reservoir. Trans Am Fish Soc (2005) 134 (3):563-71. doi: 10.1577/T03-198.1

2. Bai J, Lutz-Carrillo DJ, Quan Y, Liang S. Taxonomic Status and Genetic Diversity of Cultured Largemouth Bass (Micropterus Salmoides) in China. Aquaculture (2008) 278(1-4):27-30. doi: 10.1016/j.aquaculture.2008.03.016

3. Mao J, Wang J, Chinchar G, Chinchar V. Molecular Characterization of a Ranavirus Isolated From Largemouth Bass Micropterus Salmoides. Dis Aquat Organ (1999) 37(2):107-14. doi: 10.3354/dao037107

4. Deng G, Li S, Xie J, Bai J, Chen K, Ma D, et al. Characterization of a Ranavirus Isolated From Cultured Largemouth Bass (Micropterus Salmoides) in China. Aquaculture (2011) 312(1-4):198-204. doi: 10.1016/j.aquaculture.2010.12.032

5. Yao JY, Yuan XM, Xu Y, Yin WL, Lin LY, Pan XY, et al. Live Recombinant Lactococcus Lactis Vaccine Expressing Immobilization Antigen (I-Ag) for Protection Against Ichthyophthirius Multifiliis in Goldfish. Fish Shellfish Immunol (2016) 58:302-8. doi: 10.1016/j.fsi.2016.09.037

6. Zhu B, Zhang C, Zhao Z, Wang GX. Targeted Delivery of Mannosylated Nanoparticles Improve Prophylactic Efficacy of Immersion Vaccine Against Fish Viral Disease. Vaccines (2020) 8(1):87. doi: 10.3390/vaccines8010087

7. Wang K, Holtz KM, Anderson K, Chubet R, Mahmoud W, Cox M. Expression and Purification of an Influenza Hemagglutinin-One Step Closer to a Recombinant Protein-Based Influenza Vaccine. Vaccine (2006) 24(12):2176-85. doi: 10.1016/j.vaccine.2005.11.005

8. Lee YN, Youn HN, Kwon JH, Lee DH, Park JK, Yuk SS, et al. Sublingual Administration of Lactobacillus Rhamnosus Affects Respiratory Immune Responses and Facilitates Protection Against Influenza Virus Infection in Mice. Antiviral Res (2013) 98(2):284-90. doi: 10.1016/j.antiviral.2013.03.013

9. Yang GL, Yao JY, Yang WT, Jiang YL, Du JF, Huang HB, et al. Construction and Immunological Evaluation of Recombinant Lactobacillus Plantarum Expressing SO7 of Eimeria Tenella Fusion DC-Targeting Peptide. Vet Parasitol (2017) 236:7-13. doi: 10.1016/j.vetpar.2017.01.023

10. Zhu B, Liu GL, Gong YX, Ling F, Wang GX. Protective Immunity of Grass Carp Immunized With DNA Vaccine Encoding the Vp7 Gene of Grass Carp Reovirus Using Carbon Nanotubes as a Carrier Molecule. Fish Shellfish Immunol (2015) 42(2):325-34. doi: 10.1016/j.fsi.2014.11.026

11. Wang Z, Yu Q, Gao J, Yang Q. Mucosal and Systemic Immune Responses Induced by Recombinant Lactobacillus Spp. Expressing the Hemagglutinin of
HD, LL and ZY contributed significantly to analysis and article preparation. WY performed the data analyses. XP helped evaluate the immune efficacy. All authors contributed to the article and approved the submitted version.

\section{FUNDING}

The research was supported by the National Key R\&D Program of China (2019YFD0900104), the key project program of Huzhou City (2021GZ28, 2021GZ24, 2021GZ31), and "San Nong Liu Fang" Science and Technology Collaboration Projects (2020SNLF020).

\section{SUPPLEMENTARY MATERIAL}

The Supplementary Material for this article can be found online at: https://www.frontiersin.org/articles/10.3389/fimmu.2022. 852300/full\#supplementary-material

the Avian Influenza Virus H5N1. Clin Vaccine Immunol (2012) 19(2):174. doi: 10.1128/CVI.05618-11

12. Sim A, Lin W, Tan G, Sim M, Chow V, Alonso S. Induction of Neutralizing Antibodies Against Dengue Virus Type 2 Upon Mucosal Administration of a Recombinant Lactococcus Lactis Strain Expressing Envelope Domain III Antigen. Vaccine (2008) 26(9):1145-54. doi: 10.1016/j.vaccine.2007.12.047

13. Mohamadzadeh M, Duong T, Sandwick S, Hoover T, Klaenhammer T. Dendritic Cell Targeting of Bacillus Anthracis Protective Antigen Expressed by Lactobacillus Acidophilus Protects Mice From Lethal Challenge. Proc Natl Acad Sci USA (2009) 106(11):4331-6. doi: 10.1073/pnas.0900029106

14. Embregts CWE, Reyes-Lopez F, Pall AC, Stratmann A, Tort L, Lorenzen N, et al. Pichia Pastoris Yeast as a Vehicle for Oral Vaccination of Larval and Adult Teleosts. Fish Shellfish Immunol (2018) 85:52-60. doi: 10.1016/ j.fsi.2018.07.033

15. Guo ZR, Zhao Z, Zhang C, Jia YJ, Wang GX. Carbon Nanotubes-Loaded Subunit Vaccine Can Increase Protective Immunity Against Rhabdovirus Infections of Largemouth Bass (Micropterus Salmoides). Fish Shellfish Immunol (2020) 99:548-54. doi: 10.1016/j.fsi.2020.02.055

16. Han G, Zhai X, Wu Z, Jiang H, Xu Z. Molecular Cloning of IgT, IgD and Analysis the IgH Locus in Largemouth Bass (Micropterus Salmoides) and Immune Response Upon Bacterial Infection. Aquaculture (2021) 1):737291. doi: 10.1016/j.aquaculture.2021.737291

17. Reed LJ, Muench H. A Simple Method of Estimating Fifty Per Cent End-A Comparison of the Structural Polypeptides of Three Iridescent Viruses (Types 6, 9, and 16) and the Mapping of the DNA Region Coding for Their Major Capsid Polypeptides. Am J Epidemiol (1938) 27):493-7. doi: 10.1093/ oxfordjournals.aje.a118408

18. Chen Z, Zhao Z, Liu GY, Jian L, Wang GX, Zhu B. Immune Response and Protective Effect Against Spring Viremia of Carp Virus Induced by Intramuscular Vaccination With a SWCNTs-DNA Vaccine Encoding Matrix Protein. Fish Shellfish Immunol (2018) 79:256-64. doi: 10.1016/ j.fsi.2018.05.029

19. Villa CH, Dao T, Ahearn I, Fehrenbacher N, Casey E, Rey DA, et al. SingleWalled Carbon Nanotubes Deliver Peptide Antigen Into Dendritic Cells and Enhance IgG Responses to Tumor-Associated Antigens. ACS Nano (2011) 5 (7):5300-11. doi: 10.1021/nn200182x

20. Chen ZY, Lei XY, Zhang QY. The Antiviral Defense Mechanisms in Mandarin Fish Induced by DNA Vaccination Against a Rhabdovirus. Vet Microbiol (2012) 157(3-4):264-75. doi: 10.1016/j.vetmic.2011.12.025 
21. Yi W, Zhang X, Zeng K, Xie DF, Song C, Tam K, et al. Construction of a DNA Vaccine and Its Protective Effect on Largemouth Bass (Micropterus Salmoides) Challenged With Largemouth Bass Virus (LMBV) - ScienceDirect. Fish Shellfish Immunol (2020) 106:103-9. doi: 10.1016/j.fsi.2020.06.062

22. Liu QY, Xu MM, Dong H, Zhao JH, Wang CF. Lactobacillus Plantarum Surface-Displayed Influenza Antigens (NP-M2) With FliC Flagellin Stimulate Generally Protective Immune Responses Against H9N2 Influenza Subtypes in Chickens. Vet Microbiol (2020) 249:108834. doi: 10.1016/j.vetmic.2020.108834

23. Prystopiuk V, Feuillie C, Herman-Bausier P, Viela F, Alsteens D, Pietrocola G, et al. Mechanical Forces Guiding Staphylococcus Aureus Cellular Invasion. ACS Nano (2018) 12:3609-22. doi: 10.1021/acsnano.8b00716

24. Liu J, Yang G, Gao X, Zhang Z, Liu Y, Liu Q, et al. Recombinant Invasive Lactobacillus Plantarum Expressing Fibronectin Binding Protein A Induce Specific Humoral Immune Response by Stimulating Differentiation of Dendritic Cells. Benef Microbes (2019) 10:589-604. doi: 10.3920/BM2018.0157

25. Xue Y, Yang KD, Yu Q, Jiang YL, Wang N, Huang HB, et al. Oral Vaccination With Invasive Lactobacillus Plantarum Delivered Nucleic Acid Vaccine CoExpressing SS1 and Murine Interleukin-4 Elicits Protective Immunity Against Trichinella Spiralis in BALB/c Mice. Int Immunopharmacol (2021) 101 (PA):1081-84. doi: 10.1016/j.intimp.2021.108184

26. Dan W, Qlabc D, Yljab C, Hbhab C, Jylab C, Txpab C, et al. Oral Immunization With Recombinant Lactobacillus Plantarum Expressing Nudix Hydrolase and $43 \mathrm{kDa}$ Proteins Confers Protection Against Trichinella Spiralis in BALB/c Mice. Acta Trop (2021) 220:105947.

27. Fillatreau S, Six A, Magadan S, Castro R, Sunyer JO, Boudinot P, et al. The Astonishing Diversity of Ig Classes and B Cell Repertoires in Teleost Fish. Front Immunol (2013) 4(28):28. doi: 10.1016/j.actatropica.2021.105947

28. Zhang YA, Salinas I, Li J, Parra D, Bjork S, Xu Z, et al. IgT, a Primitive Immunoglobulin Class Specialized in Mucosal Immunity. Nat Immunol (2010) 11(9):827. doi: 10.1038/ni.1913

29. Xu Z, Takizawa F, Casadei E, Shibasaki Y, Sunyer JO. Specialization of Mucosal Immunoglobulins in Pathogen Control and Microbiota Homeostasis Occurred Early in Vertebrate Evolution. Sci Immunol (2020) 5 (44):y3254. doi: 10.1126/sciimmunol.aay3254

30. Shun Y, Yue M, Yuanxin M, Xintang Z, Shichao Q, Hui F. Molecular Cloning, Characterization, and Expression Analyses of Immunoglobulin Tau Heavy Chain (IgT) in Largemouth Bass (Micropterus Salmoides). Aquac Rep (2022) 22:100989. doi: 10.1016/j.aqrep.2021.100989

31. Tang X, Du Y, Sheng X, Xing J, Zhan W. Molecular Cloning and Expression Analyses of Immunoglobulin Tau Heavy Chain (IgT) in Turbot, Scophthalmus Maximus. Vet Immunol Immunopathol (2018) 203:1-12. doi: 10.1016/j.vetimm.2018.07.011

32. Du Y, Tang X, Zhan W, Xing J, Sheng X. Immunoglobulin Tau Heavy Chain (IgT) in Flounder, Paralichthys Olivaceus: Molecular Cloning, Characterization, and Expression Analyses. Int J Mol Sci (2016) 9(17):1571. doi: 10.3390/ijms17091571

33. Luo W, Zhang J, Wen JF, Liu H, Wang WM, Gao ZX. Molecular Cloning and Expression Analysis of Major Histocompatibility Complex Class I, IIA and IIB
Genes of Blunt Snout Bream (Megalobrama Amblycephala). Dev Comp Immunol (2014) 42(2):169-73. doi: 10.1016/j.dci.2013.08.011

34. Lie K, Somamoto T, Moore TL, Dijkstra JC, Hordvik I. Characterisation of Salmon and Trout CD8alpha and CD8beta. Mol Immunol (2005) 42 (10):1225-34. doi: 10.1016/j.molimm.2004.11.017

35. Germain RN. T-Cell Development and the CD4 CD8 Lineage Decision. Nat Rev Immunol (2002) 2:309-22. doi: 10.1038/nri798

36. Ackerman AL, Cresswell P. Cellular Mechanisms Governing Cross-Presentation of Exogenous Antigens. Nat Immunol (2004) 5(7):678. doi: 10.1038/ni1082

37. Wilson AB. MHC and Adaptive Immunity in Teleost Fishes. Immunogenetics (2017) 69(8-9):521-8. doi: 10.1007/s00251-017-1009-3

38. Pichietti S, Guerra L, Bertoni F, Randelli E, Belardinelli MC, Buonocore F, et al. (2010). Cell Mediated Intestinal Immunity in Dicentrarchus Labrax (L): Gene Expression and Functional Studies, in: First EOFFI Symposium, Viterbo (Italy), May 23e7. p. 59.

39. Ou-Yang Z, Wang P, Huang X, Jia C, Huang Y, Wei S, et al. Immunogenicity and Protective Effects of Inactivated Singapore Grouper Iridovirus (SGIV) Vaccines in Orange-Spotted Grouper, Epinephelus Coioides. Dev Comp Immunol (2012) 38(2):254-61. doi: 10.1016/j.dci.2012.07.004

40. Kai YH, Wu YC, Chi SC. Immune Gene Expressions in Grouper Larvae (Epinephelus Coioides) Induced by Bath and Oral Vaccinations With Inactivated Betanodavirus. Fish Shellfish Immunol (2014) 40(2):563-9. doi: 10.1016/j.fsi.2014.08.005

41. Ba MAHM, Stephen M, Ystein E. A Review of the Immunological Mechanisms Following Mucosal Vaccination of Finfish. Front Immunol (2015) 6:427. doi: 10.3389/fimmu.2015.00427

42. Leishman AJ. T Cell Responses Modulated Through Interaction Between CD8alpha Alpha and the Nonclassical MHC Class I Molecule, TL. Science (2001) 294(5548):1936-9. doi: 10.1126/science.1063564

Conflict of Interest: The authors declare that the research was conducted in the absence of any commercial or financial relationships that could be construed as a potential conflict of interest.

Publisher's Note: All claims expressed in this article are solely those of the authors and do not necessarily represent those of their affiliated organizations, or those of the publisher, the editors and the reviewers. Any product that may be evaluated in this article, or claim that may be made by its manufacturer, is not guaranteed or endorsed by the publisher.

Copyright (c) 2022 Yao, Zhang, Yuan, Huang, Hu, Yu, Yin, Lin, Pan, Yang, Wang, Shen and Zhang. This is an open-access article distributed under the terms of the Creative Commons Attribution License (CC BY). The use, distribution or reproduction in other forums is permitted, provided the original author(s) and the copyright owner(s) are credited and that the original publication in this journal is cited, in accordance with accepted academic practice. No use, distribution or reproduction is permitted which does not comply with these terms. 